\title{
SINGLE-PLATE SWIPE COUPLINGS ON FOUR-WHEELED VEHICLES
}

\author{
Kurniadi Rasyid', Tutur Angger Pambudi ${ }^{2}$ \\ 1,2Institut Teknologi Indonesia \\ JI. Raya Puspiptek, Setu, Kec. Serpong, Kota Tangerang Selatan, Banten 15314 \\ e-mail: kurniadirasyid@gmail.com ${ }^{1}$, tuturlastfrend@gmail.com²
}

To cite this document:

Rasyid, K., \& Pambudi, T. (2020). Single-plate Swipe Couplings On Four-wheeled Vehicles. Aptisi Transactions On Technopreneurship (ATT), 2(1), 25-33.

DOI :

https://doi.org/https://doi.org/10.34306/att.v2i1.56

\begin{abstract}
The clutch is an absolutely necessary part of the gasoline cars and the other types where the main drive is obtained from the fuel in the cylinder. The author starts planning this friction coupling with the theory and shifting system of style, then determines the type of clutch plate to be worn, determining the large diameter of the clutch shaft, specifies the thick of the friction plate, the spring reducer, the flywheel connecting Bolt with the flux, the flywheel connecting bolt with the engine shaft, the rivet connector of the friction plate with the spring disc, the rivet of the disc-connector with the sub plate, the rivet of the sub-plate and the spline hub, the rivet of the Cover flux, clutch shaft bearings, bearing holders, as well as heat calculations and age of friction plates. Specifies the type of clutch plate to be worn, determining the large diameter of the clutch shaft, determining the thick of the friction plate, the damper spring, the flywheel connecting Bolt with the flux, flywheel connecting bolt with engine shaft, rivet swipes with friction plate with disc spring, Rivet Connector Spring with sub plate, rivet sub plate rivets with spline hub, rivet fastening rivets with flux cover, clutch shaft bearings, bearing holders, as well as heat calculation and age of friction plates. Single-plate swipes are designed so that they can transmit power/rotation in a rotating or unrotating state. The type of coupling discussed here is the fixed clutch that uses a plate that serves as a medium of friction between the flywheel and the pressing plate. The purpose of writing these planning tasks to meet and complement the course of the machine element, the authors try to plan and discuss the clutch system
\end{abstract}

Keywords: Clutch, flux cover, Spline hub, bearing holder 


\section{Introduction}

The clutch is an absolutely necessary part of the gasoline cars and the other types where the main drive is obtained from the fuel in the cylinder. Beside that, with the coupling, the shifting of the transmission can be done easily without causing a sound or damage (thought) This simple will show that to change the joints will stop the vehicle, but the machine is still spinning, the shaft that it moves that should be stopped therefore the actuated shaft needs to be removed from the driven shaft. The separation or discharge and connection of the shafts is carried out using couplings operated by a lever.

The author starts planning this friction coupling with the theory and shifting system of style, then determines the type of clutch plate to be worn, determining the large diameter of the clutch shaft, specifies the thick of the friction plate, the spring reducer, the flywheel connecting Bolt with the flux, the flywheel connecting bolt with the engine shaft, the rivet connector of the friction plate with the spring disc, the rivet of the disc-connector with the sub plate, the rivet of the sub-plate and the spline hub, the rivet of the Cover flux, clutch shaft bearings, bearing holders, as well as heat calculations and age of friction plates.

For planning and calculation of the friction plate clutch for car vehicle with Power 88 $\mathrm{HP} / 6000 \mathrm{rpm}$.

The purpose of writing these planning tasks to meet and complement the course of the machine element, the authors try to plan and discuss the clutch system

\section{Research Method}

In this chapter discusses the specifics, workings and design of the swipes, friction couplings, assorted friction coupling with single plates.

\subsection{Design}

Single-plate swipes are designed so that they can transmit power/rotation in a rotating or unrotating state. The type of coupling discussed here is the fixed clutch that uses a plate that serves as a medium of friction between the flywheel and the pressing plate.

\subsubsection{Clutch image designed}

At the design of a single-plate clutch known part of the clutch section, the following is a picture of the clutch parts:

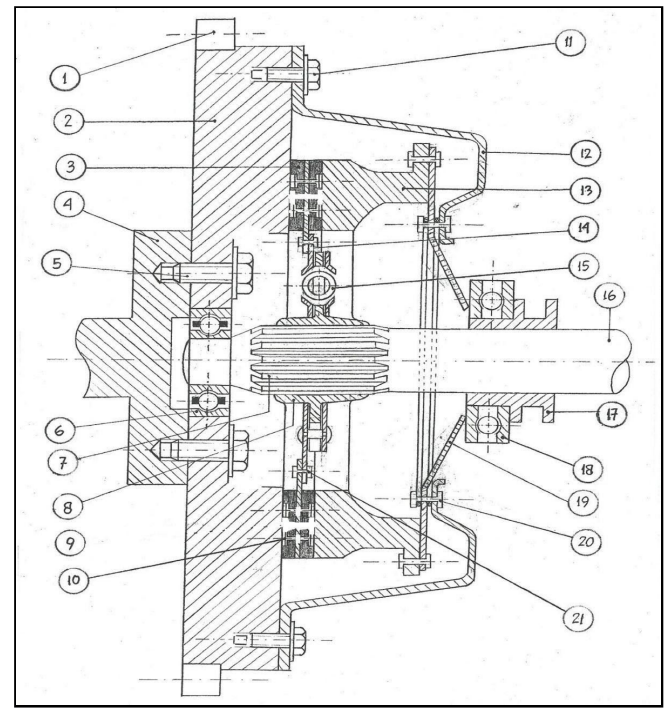

Image captions: 
1. Gears flywheel

2. Flywheel

3. Friction Plate

4. Drive SHAFT

5. Flywheel binding bolt with drive shaft

6. Radial Pads

7. Spline

8. Naf

9. Friction PLATE carrying plate

10. Friction-plate Binder Rivets

11. Clutch CAP Binding Bolt

12. Clutch Cover

13. Plate suppressor

14. Shock Spring Restraint Plate

15. Shock Springs

16. Actuated shaft

17. Sleeve

18. Axial bearing

19. Solar Spring (diaphragm)

20. Fastening rivets with a solar spring

21. Rivet

22. Rivet second-plate shock spring retaining plates.

\subsubsection{Flowchart}

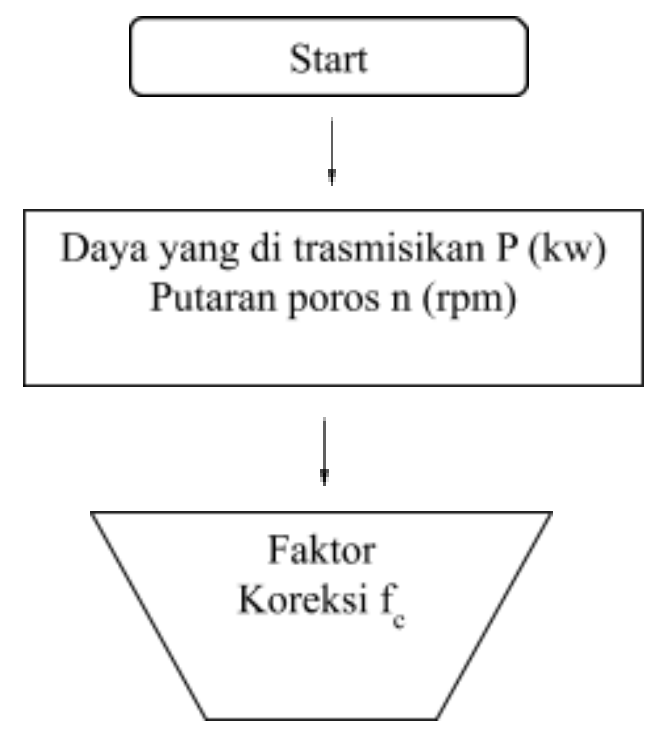




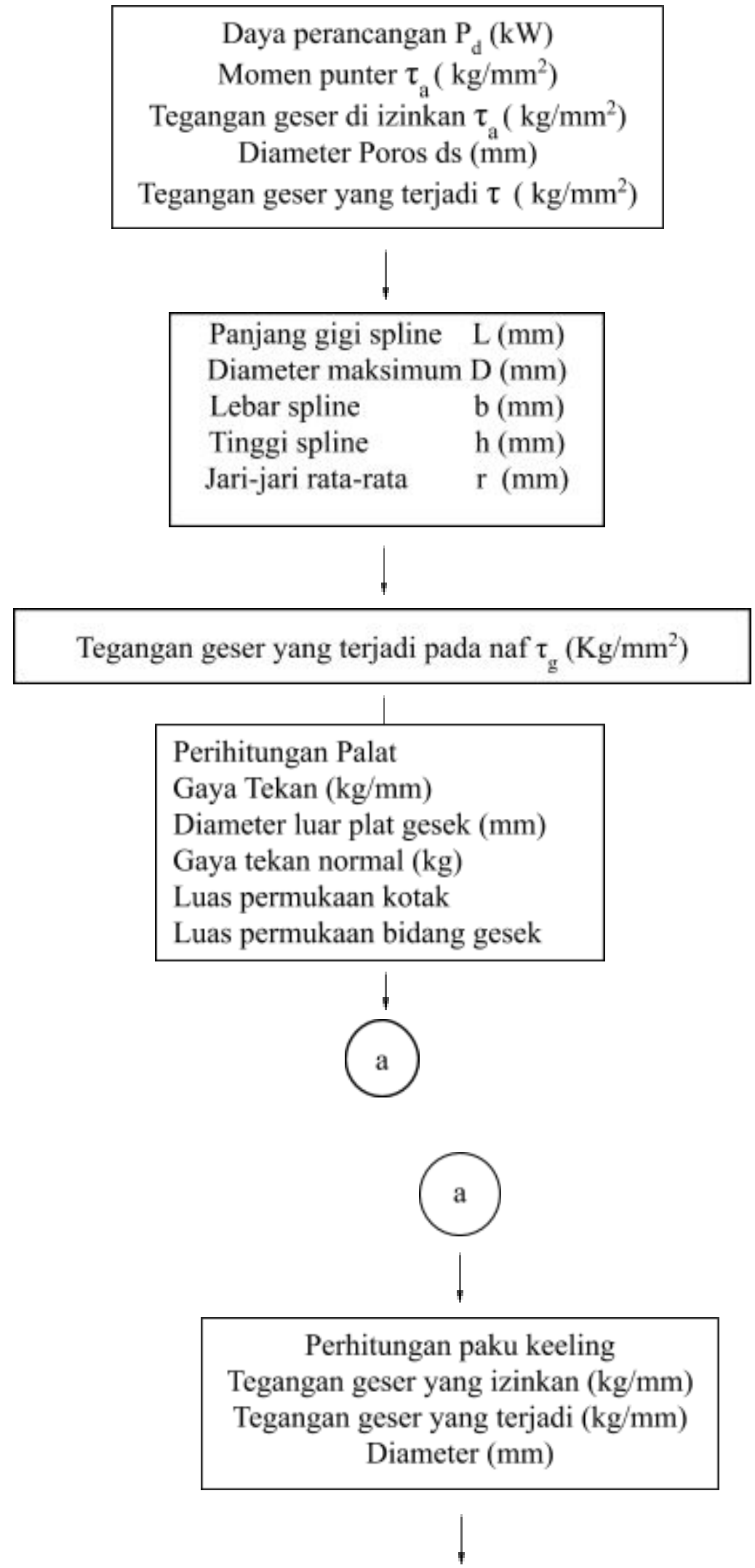




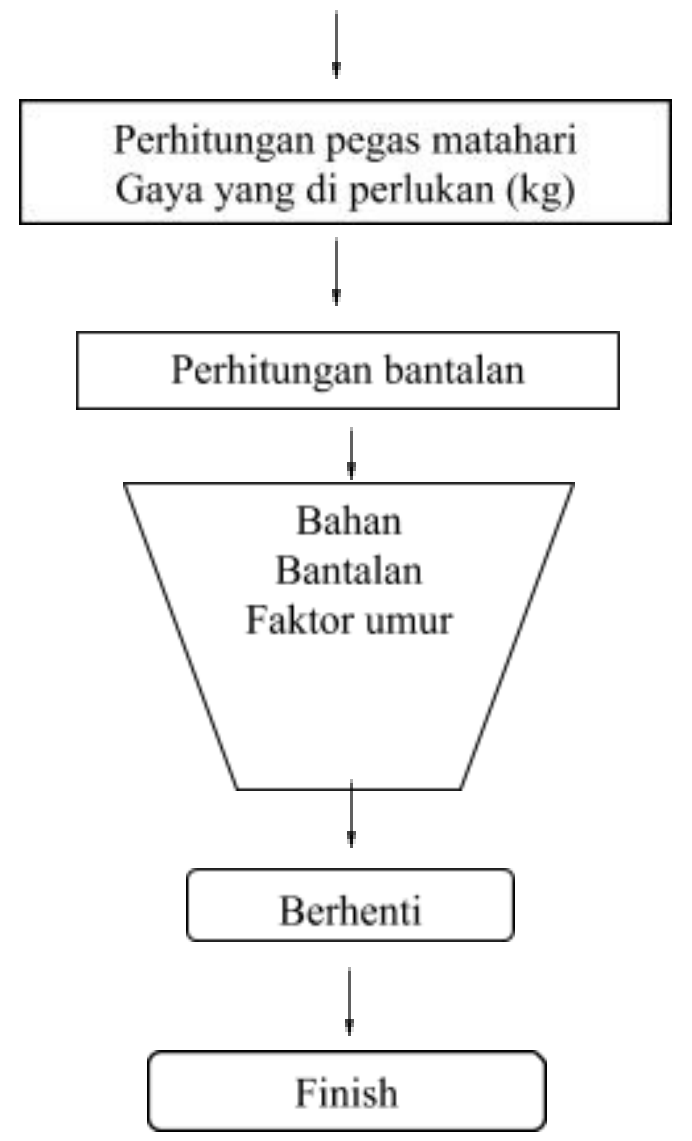

\subsection{Literature Review}

\section{Clutch}

In general, couplings are distinguished over two main parts, fixed clutch and fixed clutch. A fixed clutch is a machine element that acts as a succession of rotation and power from the drive shaft to a definite actuated shaft without a slip, where the second axis of the shaft is located on a straight line or can differ slightly Behold. While the unfixed clutch is a coupling that can be detached and connected in a rotating state.

\section{Function couplings}

Coupling has functions such as:

a. Connect the units of the manufactured shaft separately such as on the motors and generators are given for disconnection, for repair and replacement.

b. intensize mechanical flexibility on unaligned shafts.

c. Integrating protection to withstand more weights.

d. Changing the vibration characteristics of the rotational units

e. Reduce the transmission of shock loads from one shaft to another. 


\section{Things - important in clutch planning}

In planning a clutch, the following is a consideration.

a. Easy and quick installation.

b. Compact and lightweight.

c. Safe at high rounds; Vibration and small collision.

d. Nothing or little may be a prominent part.

e. Can prevent more loading.

f. There is a slight possibility of axial friction on the shaft in case of thermal expansion.

\section{Definition of friction couplings}

A friction coupling is a clutch that uses one or more plates installed between the two shafts and forms contact with the shaft so that there is a power forwarding through the friction between the neighbor. The coupling construction is quite simple and can be connected and released in rotating state. Therefore, this clutch is very much worn.

\section{Kinds of swipe couplings}

Friction couplings can be distinguished by single-plate couplings and many or plural plate couplings, i.e. the number of used friction plates, can also be divided into wet couplings and dry couplings, and can be on the basis of their work (manual, hydraulic, Numanik and electromagnetically). Which kind to use depends on the purpose, working conditions, environment and so on.

It should be noted that all couplings based on the shape (tooth, bolt, claw) are only flapping, which is to be connected at the same rotation or free rotation (idle), while a force-based friction and fluid coupling is also to connect to the Different rounds, also suitable for acceleration and RAID tasks.

In the clutch, the presence of wear and tear creates a task, that the pressing force and the attachment motion must be reordered or must be made in order not to depend on wear. The clutch should be designed to allow the muzzle casing to be detached from the load in full rotation of the clutch and arranged so that the muzzle casing is not detached on the rotating side of the drive but not on the non rotating side of the drive.

\section{Friction coupling with single Palat}

This type is used to connect the movement of the pressing spring that pushes the plate. The friction shaft is connected using a peg. Although the friction plate material varies, it should have a permit slip when the clutch gently connects the power transmission, but should not be more slip after the connection occurs. The friction factor is usually $1.2-2.0$. The clutch surface is usually made from a moulded asbestor fibers with a slightly addictive addition of the commonly used type for brake blocks and brake linings. The plate material should withstand the high temperature, the size is fitting and Lubang-lubangnya (countersunk). When high starting torque causes the clutch surface material to have a high coefficient of friction and the surface material that has a high coefficient of friction is also required.

Even for simple friction couplings, as many important terms as may be noted, the coupling can work smoothly and securely, as the clutch is an important part.

Multiple friction coupling capabilities:

a. Transmit power and rotation of motorcycle

b. Let the vehicle/motorcycle stop without having to stop the engine round

c. Can start the movement or the speed of the vehicle without the friction between the clutch plate, the friction plate does not stick continuously

d. Complete gear insertion Easily

e. Dampens vibrations due to torque occurring

f. Transmit machine torque without any slip. 


\section{Findings}

\subsection{Vehicle Specification Data 4 wheels}

1. In this task is to redesign the clutch on a four-wheeled vehicle. The following are the specifications of the Honda City type Z year 2002
Maximum power : $88 \mathrm{PS}$
Round machine $: 6000 \mathrm{rpm}$
Maximum torque : $14.4 \mathrm{kgm}$

2. Pivot Design

In the design of this material used in the design of this shaft is the steel rod used to carry high round and heavy load that is generally made of alloy steel with hardening of the skin that is resistant to wear.

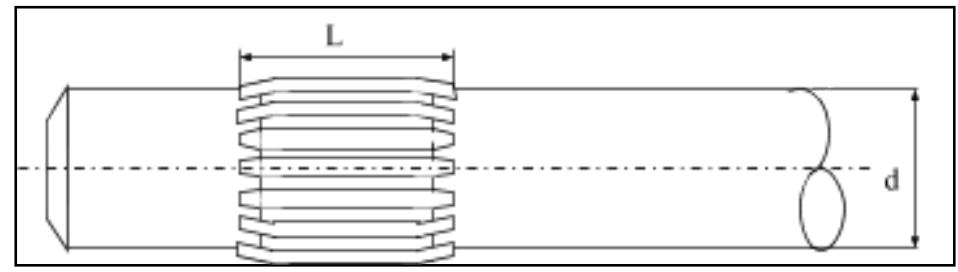

The shaft material is carbon steel with $\mathrm{S} 45 \mathrm{C}$ code, which has tensile strength of 58 $\mathrm{Kg} / \mathrm{mm} 2$ [Sularso Literature, Hal 3 table 1.1]. Here is a pivot design.

Known Data:

Maximum power $(\mathrm{P}): 64.68 \mathrm{KW}$

Round machine (n) : $6000 \mathrm{rpm}$

3. Power Calculation Plan (PD)

Correction Factor $(F C)=1.1$ (The transmitted power is the average power.

Then $\mathrm{Pd}=\mathrm{P} \times \mathrm{FC}$

$$
=64.68 \mathrm{KW} \times 1.1=71.14 \mathrm{KW}
$$

4. Puntir Moment Calculation (T)

$$
\begin{aligned}
\mathrm{T} & =9,74 \cdot 10^{5} \frac{P d}{n} \\
& =9,74 \cdot 10^{5} \frac{71,14 \mathrm{KW}}{6000 \mathrm{rpm}}=11549,7 \mathrm{~kg}-\mathrm{mm}
\end{aligned}
$$

5. Calculation of permitted shear voltages (та)

$$
\text { Unknown }
$$$$
\sigma_{b}=58 \mathrm{~kg} / \mathrm{mm}^{2}
$$$$
s f_{1}=6(\text { Voltage safety factor for } S-C \text { material })
$$$$
s f_{2}=2 \text { ( Voltage safety factor) }
$$

$$
\begin{aligned}
\mathrm{T}_{\mathrm{a}}= & \frac{\sigma_{0}}{s_{1, \mathrm{r} s \mathrm{~s}_{2}}} \\
= & \frac{58 \mathrm{~kg} / \mathrm{mm}^{2}}{6 \times 2} \\
= & 4,833 \mathrm{Kg} / \mathrm{mm}^{2}
\end{aligned}
$$

6. Calculation of shaft diameter It is known that Kt (twisting moment correction factor) $=2.5$ (large collision load) 
$\mathrm{Cb}$ (bending correction factor) $=2.2$ (flexural load occurs) then:

$$
\begin{aligned}
& \mathrm{d}_{\mathrm{s}}=\left[\frac{5.1}{\tau_{\vec{\partial}}} k_{t} \cdot C_{b} \cdot T\right]^{1 / 3} \\
= & {\left[\frac{51}{4,83 \frac{\mathrm{kg}}{\mathrm{mm}}}(2,5)(2,2)(11549,7 \mathrm{~kg}-\mathrm{mm})\right]^{1 / 3} } \\
= & 40 \mathrm{~mm}
\end{aligned}
$$

\section{Conclusion}

From the results of planning, it can be concluded as follows :

1. In the planning of the coupling, it should be known in advance what steps will be taken to make the work easy and precise.

2. Accuracy in the use of materials and units in planning the clutch is very important so that the results of the construction are correct, at least close to perfect.

3. From the results of the planning carried out can be written measurements on the planned clutch as follows :

1. For shaft planning

- Shaft material

- Shaft diameter

: S45C-D

- Poro lengths

: $40 \mathrm{~mm}$

For spline planning

- Spline material

: $200 \mathrm{~mm}$

- Spline height

: S35C-D

- Spline width

: $4.69 \mathrm{~mm}$

- Spline length

$: 4.83 \mathrm{mM}$

: $62,84 \mathrm{~mm}$

3. For friction plate planning
- Friction plate material
: Asbestos
- Outside diameter
: $229 \mathrm{~mm}$
- Inside diameter
: $137.4 \mathrm{~mm}$
- Plate thickness
: $5 \mathrm{~mm}$
- Plate width
: $46 \mathrm{~mm}$

4. For the planning of the rivet fastening of the two friction plates with the carrier plate
- Rivet material
$: \mathrm{S} 40 \mathrm{C}$
- Head diameter
$: 5 \mathrm{~mm}$
- Nail diameter
$: 3.49 \mathrm{~mm}$
- Number of rivets
: 18 buah

5. For shock spring planning

- Shock spring material : SUS 316

- Number of springs $: 4$ pieces

- Outside diameter : $20 \mathrm{~mm}$

- Inner diameter : $12 \mathrm{~mm}$

6. For solar spring / diaphragm planninga
- Spring material
: SUP' 10
- Outside diameter
: $229 \mathrm{~mm}$ 
4. After the results of the above calculations are obtained, a security check of the arising stress and component resistance is carried out.

5. From the results of the inspection it turns out that these elements are quite safe, and it can be concluded that the materials used for construction are quite safe and ready to be used on the machine.

\section{References}

[1] Colin Carmichael, Mechanical Engineers Handbook, Tokyo : Toppan Company.

[2] Khurmi. R.S. Gupta. J.K, 1980, Machine Design, New Delhi : Eurasia Publisher House.

[3] Martin, George H., dan Ir. Setiyobakti ( penerjemah ),1982, Kinematika dan Dinamika Teknik, New Jersey : McGraw Hill.

[4] Sularso dan Kiyokatsu Suga, 1994, Dasar Perencanaan dan Pemilihan Elemen Mesin, Jakarta : Pradnya Paramita.

[5] Umar Sukrisno, 1984, Bagian - bagian Mesin dan Merencana, Jakarta : Erlangga.

[6] Philip, A., Putri, C. S., \& Arifanggi, P. M. (2019). Traffic Light Timer Control Using Raspberry Pi. Aptisi Transactions On Technopreneurship (ATT), 1(2), 134-143. 